\title{
Malignant transformation of central neurocytoma with dissemination 17 years after initial treatment: illustrative case
}

\author{
Kazuhiro Kojima, MB, ${ }^{1}$ Yoshiki Arakawa, MD, PhD, ${ }^{1}$ Yasuhide Takeuchi, MD, PhD, ${ }^{2}$ Yukinori Terada, MD, PhD, ${ }^{1}$ \\ Masahiro Tanji, MD, PhD, ${ }^{1}$ Yohei Mineharu, MD, PhD, ${ }^{1}$ Hironori Haga, MD, $\mathrm{PhD},{ }^{2}$ and Susumu Miyamoto, MD, $\mathrm{PhD}{ }^{1}$ \\ Departments of ${ }^{1}$ Neurosurgery and ${ }^{2}$ Diagnostic Pathology, Kyoto University Graduate School of Medicine, Kyoto, Japan
}

BACKGROUND Central neurocytomas usually have a favorable clinical course, and gross total resection (GTR) results in long-term survival. Recurrences of central neurocytomas are usually local, and dissemination is extremely rare.

OBSERVATIONS A 24-year-old man who presented with vomiting was found to have a mass in the right lateral ventricle. After GTR, he received whole-brain irradiation and chemotherapy and had remained disease-free on follow-up for years. The review of the initial tumor revealed central neurocytoma. Seventeen years later, he presented with deterioration of memory, and magnetic resonance imaging showed an enhanced lesion in the left hippocampus. The enhanced lesion was resected, and the histological examination revealed that the tumor was a disseminated atypical central neurocytoma with frequent mitoses. Although he was treated with chemotherapy, the disseminated tumor slowly grew and invaded the brain. Massive brain invasion occurred without enhanced lesions, and he died 27 months after the tumor recurrence.

LESSONS In this patient, a central neurocytoma disseminated after an extremely long period of time. Once neurocytomas disseminate and show aggressive behavior, patients usually follow a poor course. Patients with central neurocytomas should be followed up for a long time.

https://thejns.org/doi/abs/10.3171/CASE21610

KEYWORDS central neurocytoma; atypical neurocytoma; dissemination; brain invasion; recurrence

Central neurocytomas, which are tumors with neuron-like ultrastructure, were first reported by Hassoun et al. in $1982 .{ }^{1}$ Central neurocytomas are relatively rare neuronal tumors that account for approximately $0.1-0.5 \%$ of all brain tumors, mostly affecting young adults. They are usually located in the lateral ventricles and are attached to the septum pellucidum near the foramen of Monro, although some tumors have been found in the third and fourth ventricles. $^{2}$ Central neurocytomas correspond to grade II according to the classification by the World Health Organization in $2016 .{ }^{3}$ They are usually benign, and gross total resection (GTR) usually results in long-term survival. ${ }^{2,4}$ Although atypical central neurocytoma is defined by a high MIB1 proliferation index and/or histological features of malignancy, the prognostic significance of atypical histological features remains controversial. ${ }^{5}$
Here, we report an adult man with malignant transformation of a central neurocytoma with dissemination and invasion 17 years after the initial GTR.

\section{Illustrative Case \\ Initial Clinical Course}

A 24-year-old man experienced a history of vomiting and was admitted to a local hospital. The patient had an unremarkable past medical history and no family history of malignancies. Computed tomography (CT) revealed a tumor $5 \mathrm{~cm}$ in diameter in the right lateral ventricle with hydrocephalus (data not shown because they were lost). The patient underwent placement of a ventriculoperitoneal (VP) shunt for hydrocephalus and partial resection of the tumor. Subsequently, an additional VP shunt was placed because

ABBREVIATIONS CT = computed tomography; FLAIR = fluid-attenuated inversion recovery; Gd-T1WI = gadolinium-enhanced T1-weighted imaging; $\mathrm{GTR}=$ gross total resection; ICE = ifosfamide, carboplatin, and etoposide; MRI = magnetic resonance imaging; RT = radiation therapy; STR = subtotal resection; $\mathrm{VP}=$ ventriculoperitoneal.

INCLUDE WHEN CITING Published February 7, 2022; DOI: 10.3171/CASE21610.

SUBMITTED October 24, 2021. ACCEPTED November 17, 2021.

(c) 2022 The authors, CC BY-NC-ND 4.0 (http://creativecommons.org/licenses/by-nc-nd/4.0/). 
of shunt dysfunction. The patient was referred to our hospital, and the residual tumor was totally resected via an anterior interhemispheric transcallosal approach. The patient received whole-brain radiation therapy (RT) of 59 Gy and chemotherapy with cisplatin and ranimustine on the wrong diagnosis of ependymoma.

The review of the initial tumor revealed growth of monotonous round cells with ill-defined cytoplasm and oval nuclei (Fig. 1A). No mitotic figures, tumor necrosis, or microvascular proliferations were observed. Immunohistochemically, the tumor cells were positive for synaptophysin, and the Ki-67 labeling index was $<1 \%$ (Fig. 1B). The patient was diagnosed with central neurocytoma. The patient was followed up with magnetic resonance imaging (MRI). MRI performed 16 years after the initial treatment showed no recurrent tumor on gadolinium-enhanced T1-weighted imaging (Gd-T1WI) (Fig. $1 \mathrm{C}$ and $\mathrm{D}$ ) or a fluid-attenuated inversion recovery (FLAIR) image (Fig. 1E).

\section{Clinical Course After Tumor Recurrence}

The patient presented with memory disturbance 17 years after initial treatment. MRI detected an enhanced lesion in the left hippocampus on Gd-T1WI (Fig. 2A and B) and hyperintense lesions in the left hippocampus and the right temporal lobe on FLAIR images (Fig. 2C). Cerebrospinal fluid cytology detected disseminated tumor cells (Fig. 2D).

The tumor in the left hippocampus was partially removed via a left subtemporal approach. Histopathological examinations of the resected tumor revealed growth of monotonous round cells with frequent mitoses (seven per 10 high-power fields) (Fig. 2E). Immunohistochemically, the tumor cells were positive for synaptophysin (Fig. 2F) and negative for glial fibrillary acidic protein and neurofilament, and the Ki-67 labeling index was $\sim 34 \%$ (Fig. 2G). Based on these findings, the lesion was diagnosed as a disseminated atypical central neurocytoma.

The patient was treated with temozolomide $150-200 \mathrm{mg} / \mathrm{m}^{2}$ for 5 days during each 28-day cycle. Two months after the third resection surgery, an enhanced lesion on Gd-T1WI was detected in the right temporal lobe, and the hyperintense lesions on the FLAIR image were enlarged in the right temporal lobe (Fig. $3 A$ and $B$ ). Although the patient was treated with seven cycles of temozolomide, the enhanced lesion on Gd-T1Wl grew in the right temporal lobe, and the hyperintense lesions on the FLAIR image enlarged in the left hippocampus and the right temporal lobe 8 months after the third surgery (Fig. $3 \mathrm{C}$ and $\mathrm{D}$ ). The patient received chemotherapy with ifosfamide $\left(750 \mathrm{mg} / \mathrm{m}^{2} /\right.$ day on days 1,2 , and 3), carboplatin (75 $\mathrm{mg} / \mathrm{m}^{2} /$ day on days 1,2 , and 3 ), and etoposide $\left(75 \mathrm{mg} / \mathrm{m}^{2} /\right.$ day on days 1,2 , and 3 ) (ICE) every 4 to 6 weeks.

The cognitive dysfunction of the patient gradually worsened. Subsequent MRI showed slow enlargement of hyperintense lesions on FLAIR images in both temporal lobes. After the patient received nine courses of ICE chemotherapy 18 months after the third surgery, MRI showed massive brain invasion of the tumor without enhanced lesions on Gd-T1WI (Fig. 3E and F). As activities of daily
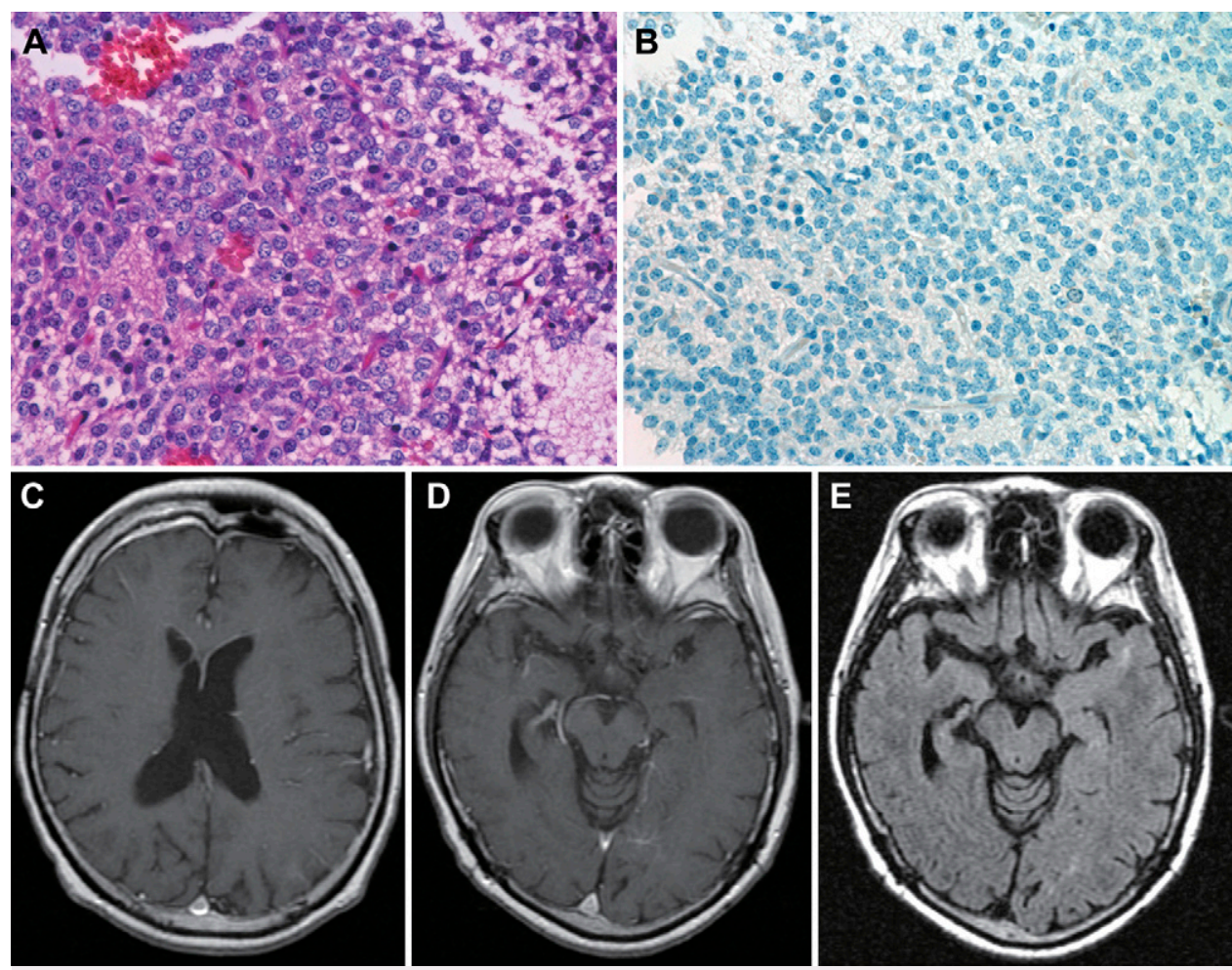

FIG. 1. Histopathological examination of the primary tumor and MRI taken 16 years after the initial treatment. A: The tumor was composed of monotonous growth of round cells with ill-defined cytoplasm and oval nuclei. No mitosis was observed (hematoxylin and eosin stain, original magnification $\times 40$ ). B: The Ki-67 labeling index was $<1 \%$ (Ki-67 stain, original magnification $\times 40$ ). Gd-T1WI (C and D) and FLAIR image $(\mathrm{E})$ detected no recurrent tumor 16 years after the initial treatment. 

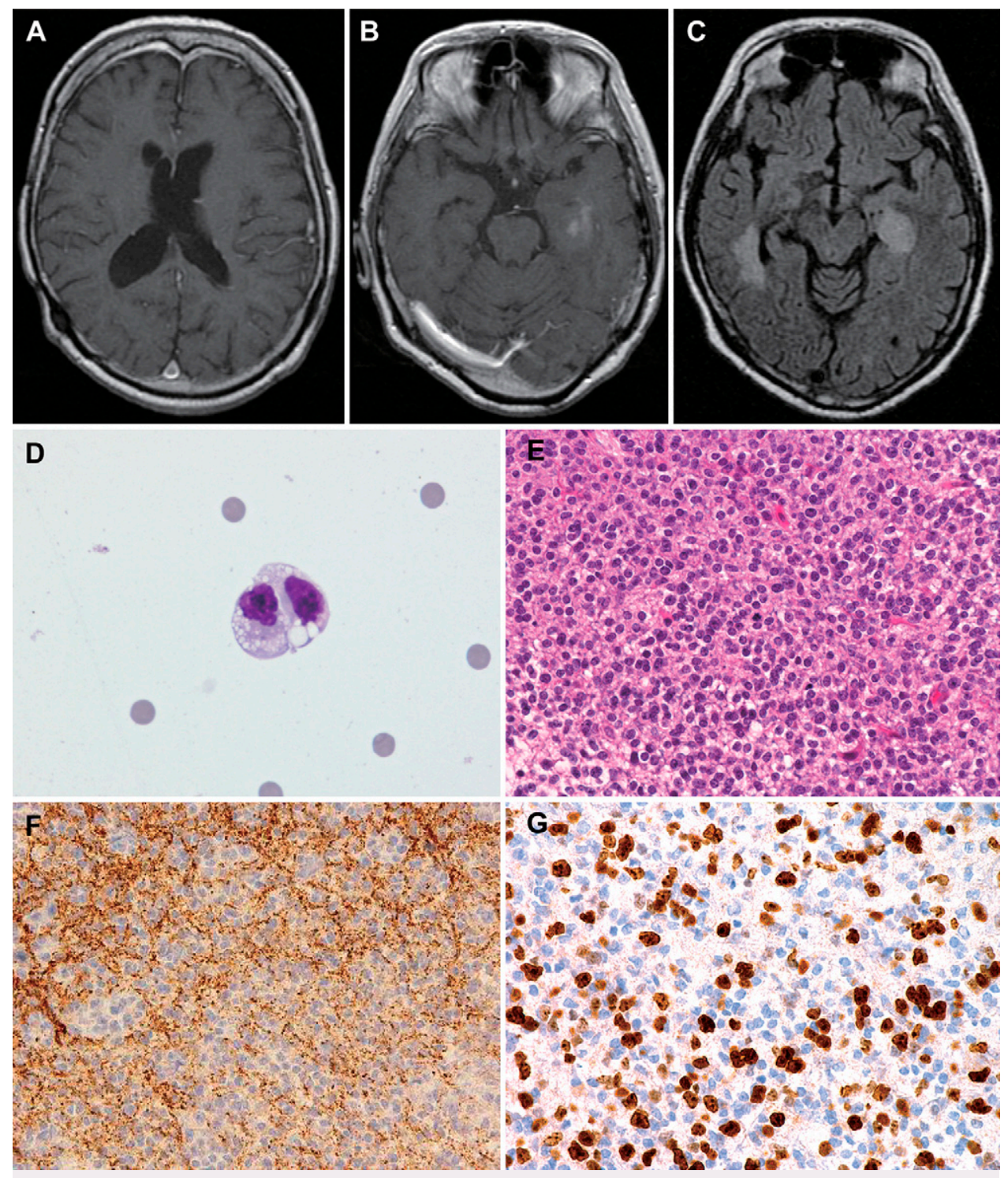

FIG. 2. MRI obtained 17 years after the initial treatment and histopathological examinations of the recurrent tumor. Gd-T1WI (A and B) showed the enhanced lesion in the left hippocampus 17 years after the initial treatment. FLAIR image (C) showed hyperintense lesions in the left hippocampus and the right temporal lobe. D: Cerebrospinal fluid cytology detected disseminated tumor cells. E: The tumor was composed of monotonous growth of round cells (hematoxylin and eosin stain, original magnification $\times 40$ ). Mitotic figures were frequently observed (seven per 10 high-power fields). F: Most of the tumor cells were immunoreactive for synaptophysin (synaptophysin stain, original magnification $\times 40$ ). G: The Ki-67 labeling index was $34 \%$ (Ki-67 stain, original magnification $\times 40$ ).

living deteriorated, the patient selected hospice care and passed away 27 months after the tumor recurrence.

\section{Discussion \\ Observations}

Although central neurocytomas may cause symptoms associated with increased intracranial pressure, the clinical courses are usually benign. $^{2}$ The 10-year survival exceeds $90 \%$, and the recurrence rate is relatively low $(\sim 30 \%){ }^{4}$ The Ki-67 labeling index is used as an important predictive marker of prognosis and relapse for central neurocytoma. Söylemezoglu et al. observed that patients with a Ki-67 labeling index of $>2 \%$ had a recurrence rate of $63 \%$, whereas patients with a Ki-67 labeling index of $<2 \%$ had a recurrence rate of only $22 \%$ over a 150 -month period. These authors concluded that a Ki-67 labeling index of $>2 \%$ may be related to a more malignant course. ${ }^{6}$ Similarly, Rades et al. compared patients with a Ki-67 labeling index of $\leq 3 \%(n=87)$ with those with a Ki-67 labeling index of $>3 \%(n=36),{ }^{7}$ and they concluded that a Ki-67 labeling index of $>3 \%$ correlates with a worse prognosis for local control (5-year local control: $\leq 3 \%, 87 \% ;>3 \%, 38 \%$ ) and survival (5-year over survival: $\leq 3 \%, 95 \% ;>3 \%, 66 \%$ ). Thus, neurocytomas 

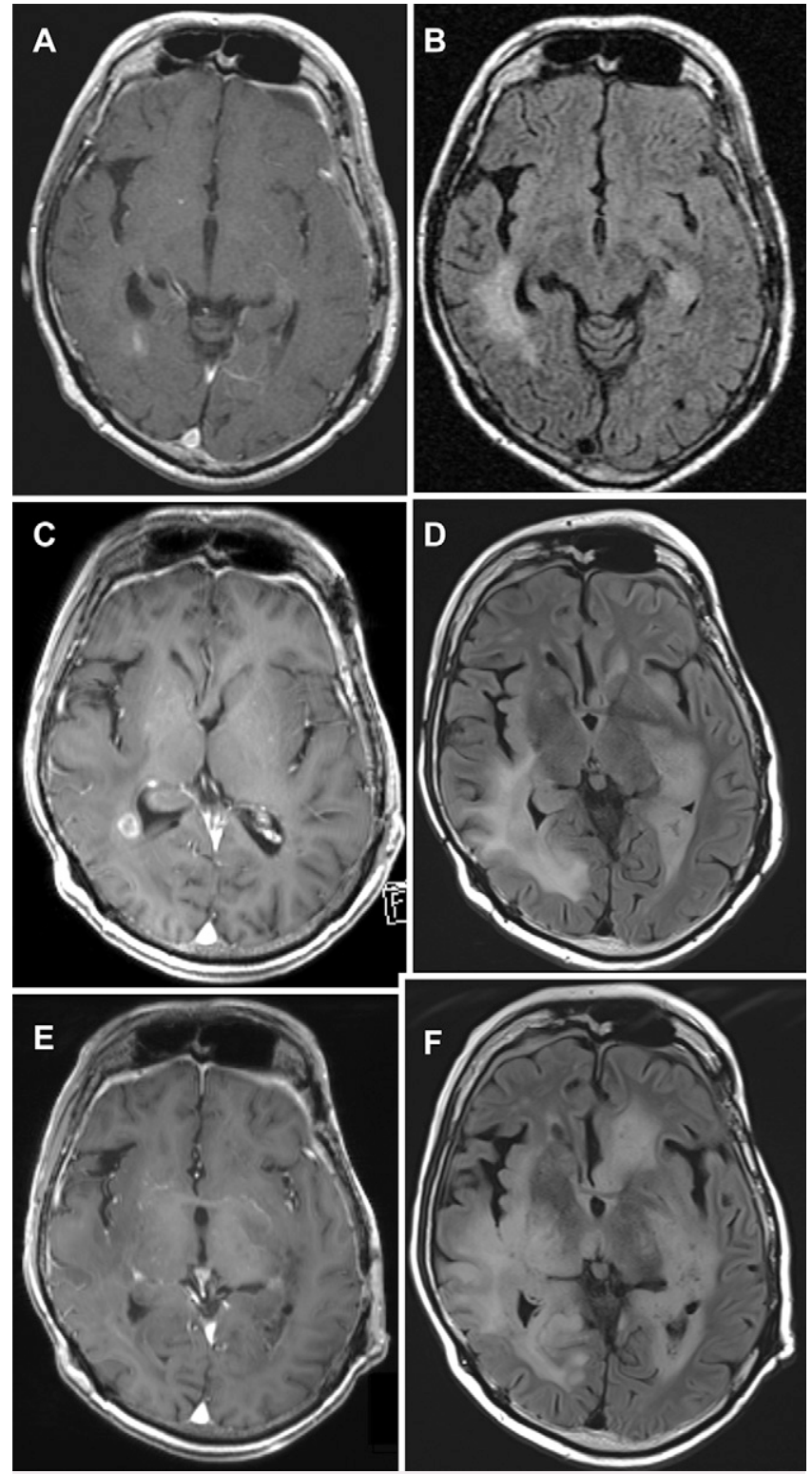

FIG. 3. MRI obtained 2, 8, and 18 months after the third resective surgery for tumor recurrence. The enhanced lesion on Gd-T1WI (A) was detected in the right temporal lobe 2 months after the third surgery. The hyperintense lesions on the FLAIR image (B) were enlarged in the right temporal lobe. The enhanced lesion on Gd-T1WI (C) grew in the right temporal lobe during temozolomide treatment 8 months after the third surgery. The hyperintense lesions on the FLAIR image (D) were enlarged in the left hippocampus and the right temporal lobe. No enhanced lesion on Gd-T1WI (F) was detected during ICE treatments 18 months after the third surgery. The hyperintense lesions on the FLAIR image $(\mathbf{G})$ were enlarged in both cerebral hemispheres, which showed massive tumor invasion.

with a Ki-67 labeling index of $>2-3 \%$ and/or histological atypia such as necrosis, increased mitoses, or vascular proliferation are termed atypical. ${ }^{4,6-8}$ Furthermore, Imber et al. found that a Ki-67 labeling index of $>4 \%$ is associated with a significantly higher risk of tumor progression compared to a Ki-67 labeling index of $\leq 4 \%$ (2-year progression free survival: $>4 \%, 48 \% ; \leq 4 \%, 90 \%$ ), and they proposed the use of a Ki- 67 labeling index of $4 \%$ as a cut-off for atypical tumors. ${ }^{9}$ However, the prognostic significance of atypical features remains controversial. Vasiljevic et al. showed that the histological atypical features and the high MIB1 index were not predictors of a higher risk of recurrence in 71 patients with central neurocytoma.

Treatments for central neurocytomas are mainly resection and RT. Rades et al. reviewed and analyzed 438 reports of neurocytomas, including 73 children and 365 adults. The authors defined atypical lesions as tumors that showed atypical histological features or a Ki-67 labeling index of $>3 \%$ and provided treatment recommendations for typical neurocytomas, atypical neurocytomas, and neurocytomas in children, as described below. ${ }^{4}$ GTR yields the best prognosis for both survival and local control, with 99\% 5-year survival and $85 \%$ 5-year local control rate. After subtotal resection (STR), adjuvant RT significantly improves survival (5-year overall survival: no RT, $82 \%$; adjuvant RT, $89 \%$ ) and local control (5-year local control: no RT, 41\%; adjuvant RT, $83 \%$ ). As for the radiation dose, the authors recommended 50-54 Gy for typical lesions, 56-60 Gy for atypical lesions, and 50 Gy for lesions in children. Some studies reported that stereotactic radiosurgery has favorable local control in small lesions. ${ }^{10,11}$

Recurrences of central neurocytomas are usually local. We reviewed 16 patients with central neurocytomas that recurred with dissemination (Table 1). ${ }^{10,12-24}$ The mean age of onset was 30.6 years (range 3-56 years). Of the 16 cases, 10 were men and 6 were women. The primary tumors arose from the subarachnoid space $(n=1)$, septum pellucidum ( $n=3)$, fornix, or walls of the ventricles (lateral ventricles: $n=10$; third ventricles: $n=2$ ). The initial Ki-67 labeling index was available in 11 cases, and the average was $15.4 \%$ (range $0-37.3 \%$ ). Five patients received GTR, one received GTR+RT, five received STR, and five received STR+RT for the primary lesions. The mean period between the primary surgery and dissemination was 26.2 months (range 0 to 117 months). In analysis according to treatment, the mean period was 49.4 months (range 17 to 117 months) after GTR, 37.0 months after GTR+RT, 14.6 months (range 0 to 45 months) after STR, and 11.4 months (range 2 to 24 months) after STR $+\mathrm{RT}$.

A total of 22 treatments were carried out after dissemination. Only seven resections were performed (GTR: $n=1$; STR: $n=3$; STR+RT: $n=3)$, and the tumors were removed from the spinal cord $(n=3)$ and cerebral ventricle $(n=4)$. Ki-67 labeling indexes were examined in six cases; in four of six cases, the Ki-67 index was elevated compared to the initial index. The mean Ki-67 labeling index was 16.2\% (range $4.1-40 \%$ ). Ki-67 labeling indexes were elevated by an average of $9.9 \%$ (range $2.3-15 \%$ ) in the elevated cases. RT or chemotherapy was carried out in all but four cases. A variety of RT techniques, doses, and cytotoxic agents was used. Mozes et al. reviewed 19 cases with malignant clinical courses and concluded that adjuvant neuroaxis irradiation should be considered in cases with histologically atypical findings and/or high Ki-67 labeling indexes because of the high possibility of spread via the cerebrospinal fluid. ${ }^{13}$ The role of chemotherapy is still uncertain in the treatment of central neurocytomas. In disseminated cases, some response was reported with regimens including temozolomide, cyclophosphamide, cisplatin, topotecan, carboplatin, ifosfamide, and etoposide. ${ }^{13,15,23}$ There is a case report that chemotherapy alone resulted in complete tumor remission with topotecan, ifosfamide, and carboplatin. ${ }^{23}$ Our patient was treated with temozolomide for the 
TABLE 1. Sixteen patients with central neurocytomas that recurred with dissemination

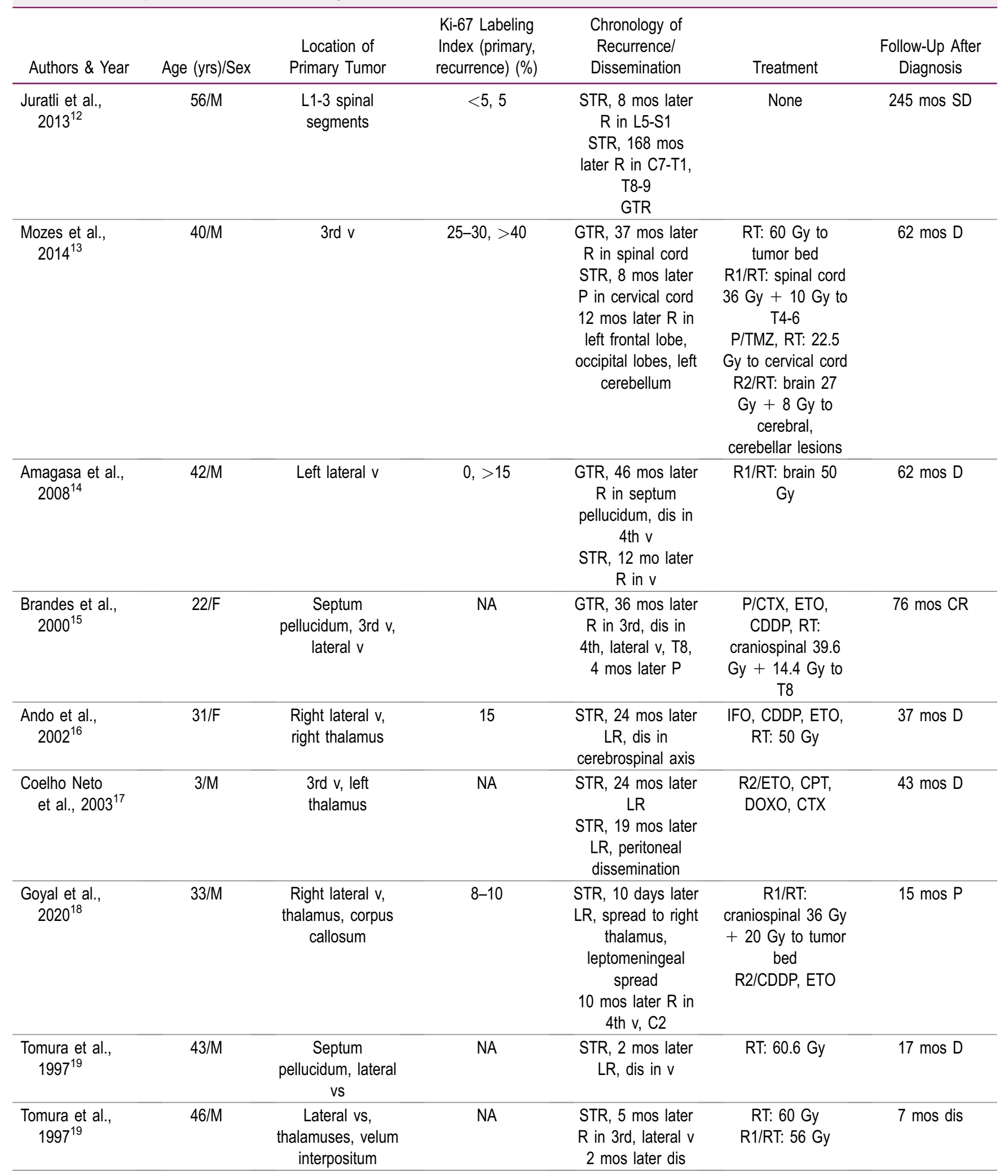


TABLE 1. Sixteen patients with central neurocytomas that recurred with dissemination

\begin{tabular}{|c|c|c|c|c|c|c|}
\hline Authors \& Year & Age (yrs)/Sex & $\begin{array}{c}\text { Location of } \\
\text { Primary Tumor }\end{array}$ & $\begin{array}{l}\text { Ki-67 Labeling } \\
\text { Index (primary, } \\
\text { recurrence) (\%) }\end{array}$ & $\begin{array}{l}\text { Chronology of } \\
\text { Recurrence/ } \\
\text { Dissemination }\end{array}$ & Treatment & $\begin{array}{c}\text { Follow-Up After } \\
\text { Diagnosis }\end{array}$ \\
\hline $\begin{array}{l}\text { Vemavarapu } \\
\text { et al., } 2014^{21}\end{array}$ & $44 / F$ & $\begin{array}{l}\text { Left lateral v, } \\
\text { atrium }\end{array}$ & 15,5 & $\begin{array}{l}\text { STR, } 14 \text { mos later } \\
\mathrm{R} \text { in left occipital } \\
\text { lobe, left posterior } \\
\text { lobe, cerebellar } \\
\text { vermis, left } \\
\text { cerebellar } \\
\text { hemisphere }\end{array}$ & $\begin{array}{c}\text { Proton radiation, } \\
\text { TMZ, Bmab, ADM, } \\
\text { IFO, TMZ }\end{array}$ & 14 mos $P$ \\
\hline $\begin{array}{l}\text { Matsunaga et al., } \\
2010^{10}\end{array}$ & $41 / F$ & Left lateral v & NA & $\begin{array}{c}\text { GTR, } 98 \text { mos later } \\
\text { LR } \\
19 \text { mos later } R \\
\text { STR, } 25 \text { mos later } \\
\text { R in left lateral v } \\
19 \text { mos later P } \\
\text { STR, } 17 \text { mos later } \\
\text { LR }\end{array}$ & $\begin{array}{l}\text { R1/RT: } 25 \text { Gy } \\
\text { R2/SRS: } 12 \text { Gy } \\
\text { R3/SRS: } 12 \text { Gy }\end{array}$ & $192 \operatorname{mos} D$ \\
\hline $\begin{array}{l}\text { Eng et al., } \\
1997^{22}\end{array}$ & $22 / F$ & $\begin{array}{c}\text { Septum } \\
\text { pellucidum, 3rd v, } \\
\text { lateral v }\end{array}$ & 3.3 & $\begin{array}{c}\text { GTR, } 36 \text { mos later } \\
\text { LR, dis in lateral \& } \\
\text { 4th v, T8, } 4 \text { mos } \\
\text { later } P\end{array}$ & $\begin{array}{l}\text { P/ETO, CDDP, } \\
\text { CTX }\end{array}$ & 40 mos \\
\hline $\begin{array}{l}\text { Eng et al., } \\
1997^{22}\end{array}$ & $22 / F$ & $\begin{array}{c}\text { Right lateral v, 3rd } \\
\qquad \mathrm{r}\end{array}$ & $1.8,4.1$ & $\begin{array}{l}\text { STR, } 20 \text { mos later } \\
\text { R in lateral vs } \\
\text { STR, } 14 \text { mos later } \\
\text { LR, dis in spinal } \\
\text { leptomeninges }\end{array}$ & $\begin{array}{c}\text { R2/ETO, CDDP, } \\
\text { CTX }\end{array}$ & $34 \mathrm{mos}$ \\
\hline $\begin{array}{l}\text { Ogawa et al., } \\
2006^{24}\end{array}$ & $34 / M$ & Corpus callosum & 25 & $\begin{array}{c}\text { STR, } 12 \text { mos later } \\
\text { LR, dis around } \\
\text { CSF }\end{array}$ & $\begin{array}{c}\text { SRS: } 25 \text { Gy } \\
\text { R1/RT: } 60 \text { Gy, } \\
\text { CDDP, ETO, CTX }\end{array}$ & 23 mos $D$ \\
\hline
\end{tabular}

$\mathrm{ADM}=$ Adriamycin; Ara-C = cytarabine; $\mathrm{Bmab}=$ bevacizumab; $\mathrm{CDDP}=$ cisplatin; $\mathrm{CPT}=$ carboplatin; $\mathrm{CR}=$ complete remission; $\mathrm{CSF}=$ cerebrospinal fluid; $\mathrm{CTX}=$ cyclophosphamide; $\mathrm{D}=$ died; dis = dissemination; $\mathrm{DOXO}=$ doxorubicin; $\mathrm{ETO}=$ etoposide; IFO = ifosfamide; $\mathrm{LR}=$ local recurrence; $\mathrm{NA}=$ no assessment; $\mathrm{P}=$ progression; $\mathrm{R}=$ recurrence; $\mathrm{SD}=$ stable disease; $T E P A=$ thiotepa; $T M Z$ = temozolomide; TOPO = topotecan; $v$ = ventricle; $\mathrm{VCR}=$ vincristine. 
first relapse and ICE for the second relapse. Chemotherapy with temozolomide and ICE may result in slow progression for a long period.

Clinical outcomes were reported in 14 of 16 disseminated cases that we reviewed. Eight patients died because of disease progression. The mean survival after dissemination was 21.0 months (range 0 to 87 months). At the time of the last follow-up, two patients were in complete remission, three had progressive disease, and one had stable disease. The mean follow-up period was 59.3 months (range 7 to 245 months). Additionally, the mean recurrence-free survival after dissemination was 12.1 months (range 2 to 168 months). In our case, central neurocytoma with a Ki-67 labeling index of $<1 \%$ recurred and disseminated 17 years after GTR, and the patient died 27 months after the recurrence. Compared with other cases, the tumor had a low initial Ki67 labeling index and disseminated after an extremely long period of time. In terms of the clinical course after dissemination, in many disseminated cases, including this case, patients followed an aggressive course, and the prognosis was relatively unfavorable. Based on the above results, we recommend long-term follow-up for all patients with central neurocytomas.

\section{Lessons}

We reported a patient with malignant transformation of central neurocytoma with dissemination after a long period of 17 years. Compared with other cases, the tumor in our patient's case disseminated after an extremely long period of time. Once neurocytomas disseminate, patients usually follow an aggressive course. Therefore, patients with central neurocytomas should be followed up for a long time even if the tumors have a low Ki-67 labeling index or lack atypical features on histopathological examination.

\section{References}

1. Hassoun J, Gambarelli D, Grisoli F, et al. Central neurocytoma. An electron-microscopic study of two cases. Acta Neuropathol. 1982; 56(2):151-156.

2. Lee SJ, Bui TT, Chen $\mathrm{CH}$, et al. Central neurocytoma: a review of clinical management and histopathologic features. Brain Tumor Res Treat. 2016;4(2):49-57.

3. Louis DN, Ohgaki $\mathrm{H}$, Wiestler OD, et al. WHO Classification and Grading of Tumours of the Central Nervous System. International Agency for Research on Cancer. IARC Press; 2016.

4. Rades D, Schild SE. Treatment recommendations for the various subgroups of neurocytomas. J Neurooncol. 2006;77(3):305-309.

5. Vasiljevic A, François P, Loundou A, et al. Prognostic factors in central neurocytomas: a multicenter study of 71 cases. Am J Surg Pathol. 2012;36(2):220-227.

6. Söylemezoglu F, Scheithauer BW, Esteve J, Kleihues P. Atypical central neurocytoma. J Neuropathol Exp Neurol. 1997;56(5):551-556.

7. Rades D, Schild SE, Fehlauer F. Prognostic value of the MIB-1 labeling index for central neurocytomas. Neurology. 2004;62(6):987-989.

8. Hassoun J, Söylemezoglu F, Gambarelli D, Figarella-Branger D, von Ammon K, Kleihues P. Central neurocytoma: a synopsis of clinical and histological features. Brain Pathol. 1993;3(3):297-306.

9. Imber BS, Braunstein SE, Wu FY, et al. Clinical outcome and prognostic factors for central neurocytoma: twenty year institutional experience. J Neurooncol. 2016;126(1):193-200.

10. Matsunaga S, Shuto T, Suenaga J, et al. Gamma Knife radiosurgery for central neurocytomas. Neurol Med Chir (Tokyo). 2010; 50(2):107-113.

11. Bui TT, Lagman C, Chung LK, et al. Systematic analysis of clinical outcomes following stereotactic radiosurgery for central neurocy- toma. Brain Tumor Res Treat. 2017;5(1):10-15.

12. Juratli TA, Geiger K, Leimert M, Schackert G, Kirsch M. Atypical central neurocytoma with recurrent spinal dissemination over a period of 20 years: a case report and review of the literature. Case Rep Neurol Med. 2013;2013:925647.

13. Mozes P, Szanto E, Tiszlavicz L, et al. Clinical course of central neurocytoma with malignant transformation-an indication for craniospinal irradiation. Pathol Oncol Res. 2014;20(2):319-325.

14. Amagasa M, Yuda F, Sato S, Kojima H. Central neurocytoma with remarkably large rosette formation and rapid malignant progression: a clinicopathological follow-up study with autopsy report. Clin Neuropathol. 2008;27(4):252-257.

15. Brandes AA, Amistà $P$, Gardiman $M$, et al. Chemotherapy in patients with recurrent and progressive central neurocytoma. Cancer. 2000;88(1):169-174.

16. Ando $\mathrm{K}$, Ishikura R, Morikawa $\mathrm{T}$, et al. Central neurocytoma with craniospinal dissemination. Magn Reson Med Sci. 2002;1(3):179-182.

17. Coelho Neto M, Ramina R, de Meneses MS, Arruda WO, Milano JB. Peritoneal dissemination from central neurocytoma: case report. Arq Neuropsiquiatr. 2003;61(4):1030-1034.

18. Goyal S, Kataria T, Gupta D, Dhyani A, Mohapatra I, Narang KS. Atypical central neurocytoma with leptomeningeal dissemination: a case report. J Egypt Natl Canc Inst. 2020;32(1):23.

19. Tomura $\mathrm{N}$, Hirano $\mathrm{H}$, Watanabe $\mathrm{O}$, et al. Central neurocytoma with clinically malignant behavior. AJNR Am J Neuroradiol. 1997;18(6): 1175-1178.

20. Choi YSSY, Huh KY, Kim KU. Malignant variant of central neurocytoma. J Korean Neurosurg Soc. 2004;35(3):313-316.

21. Vemavarapu L, Czyszczon I, Parker JCJr, Wagner S, Vitaz T, Parker JR. Atypical central neurocytoma with sarcomatous differentiation. Arch Pathol Lab Med. 2014;138(9):1233-1237.

22. Eng DY, DeMonte F, Ginsberg L, Fuller GN, Jaeckle K. Craniospinal dissemination of central neurocytoma. Report of two cases. $J$ Neurosurg. 1997;86(3):547-552.

23. Amini E, Roffidal T, Lee A, et al. Central neurocytoma responsive to topotecan, ifosfamide, carboplatin. Pediatr Blood Cancer. 2008;51(1):137-140.

24. Ogawa Y, Sugawara T, Seki H, Sakuma T. Central neurocytomas with MIB-1 labeling index over $10 \%$ showing rapid tumor growth and dissemination. J Neurooncol. 2006;79(2):211-216.

\section{Disclosures}

Dr. Arakawa reported grants from Siemens, Philips, Sanofi, Nihon MediPhysics, Mitsubishi Tanabe, Takeda, Stryker, Astellas Pharma, Taiho Pharma, Pfizer, Ono Pharmaceutical, Brainlab, Merck, Chugai, Eisai, Meiji Seika, Daiichi Sankyo, Zeiss, and CLS Behring; personal fees from Nippon Kayaku, AbbVie, Novocure, UCB Japan, Otsuka, Ono Pharmaceutical, Brainlab, Merck, Chugai, Eisai, Meiji Seika, Daiichi Sankyo, Zeiss, and CLS Behring outside the submitted work.

\section{Author Contributions}

Conception and design: Arakawa, Kojima. Acquisition of data: Arakawa, Kojima, Takeuchi, Haga. Analysis and interpretation of data: Kojima, Takeuchi. Drafting the article: Arakawa, Kojima, Takeuchi. Critically revising the article: Arakawa, Takeuchi, Terada, Tanji, Mineharu, Miyamoto. Reviewed submitted version of manuscript: Arakawa, Kojima, Miyamoto. Approved the final version of the manuscript on behalf of all authors: Arakawa. Administrative/technical/material support: Arakawa, Miyamoto. Study supervision: Miyamoto.

\section{Correspondence}

Yoshiki Arakawa: Kyoto University Graduate School of Medicine, Kyoto, Japan. yarakawa@kuhp.kyoto-u.ac.jp. 